Supporting Information for:

\title{
Characterization of Cake Layer in Submerged Membrane Bioreactor
}

\author{
Fangang Meng, Hanmin Zhang*, Fenglin Yang
}

School of Environmental and Biological Science and Technology, Dalian University of Technology, Dalian 116024, P.R. China

Submitted to

Environmental Science and Technology

\footnotetext{
*Corresponding author phone: 86-411-84706172

fax: $86-411-84708084$

Email: zhanghanmin00@126.com
} 
Table S1 Components of membrane foulants measured by XRF system

\begin{tabular}{llllllllllllll}
\hline \multicolumn{1}{c}{ Items } & \multicolumn{1}{c}{10} & & & & & & & & \\
\hline Element & $\mathrm{P}_{2} \mathrm{O}_{5}$ & $\mathrm{SiO}_{2}$ & $\mathrm{CaO}$ & $\mathrm{SO}_{3}$ & $\mathrm{~K}_{2} \mathrm{O}$ & $\mathrm{Fe}_{2} \mathrm{O}_{3}$ & $\mathrm{Al}_{2} \mathrm{O}_{3}$ & $\mathrm{MgO}$ & $\mathrm{ZnO}$ & $\mathrm{Cl}$ & $\mathrm{CuO}$ & $\mathrm{SrO}$ & $\mathrm{Sum}$ \\
$\mathrm{Kcps}$ & 7.9 & 3.1 & 10.7 & 6.1 & 7.9 & 1.8 & 0.7 & 0.8 & 1.1 & 1.3 & 0.6 & 1.4 & \\
Percent & 35.7 & 13.7 & 13.2 & 11. & 8.51 & 7.38 & 4.52 & 2.22 & 1.53 & 1.36 & 0.225 & 0.132 & 100 \\
$(\%)$ & & & & 5 & & & & & & & & & \\
\hline
\end{tabular}

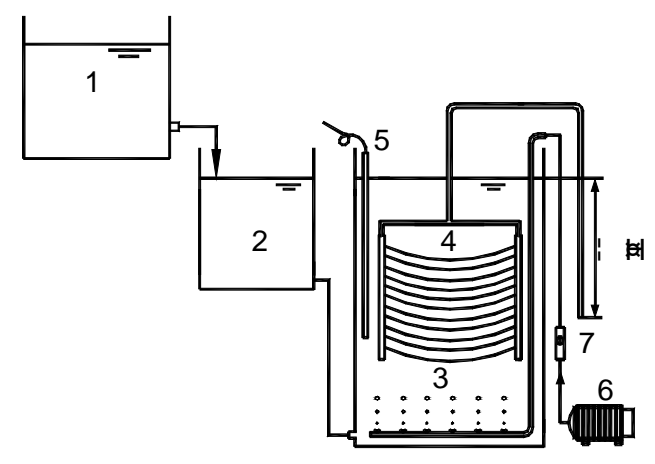

FIGURE S1 Schematic of the membrane bioreactor

1-feed tank, 2-balance box, 3-bioreactor, 4-membrane module, 5-electric heater, 6-air pump, 7-air flow meter. 


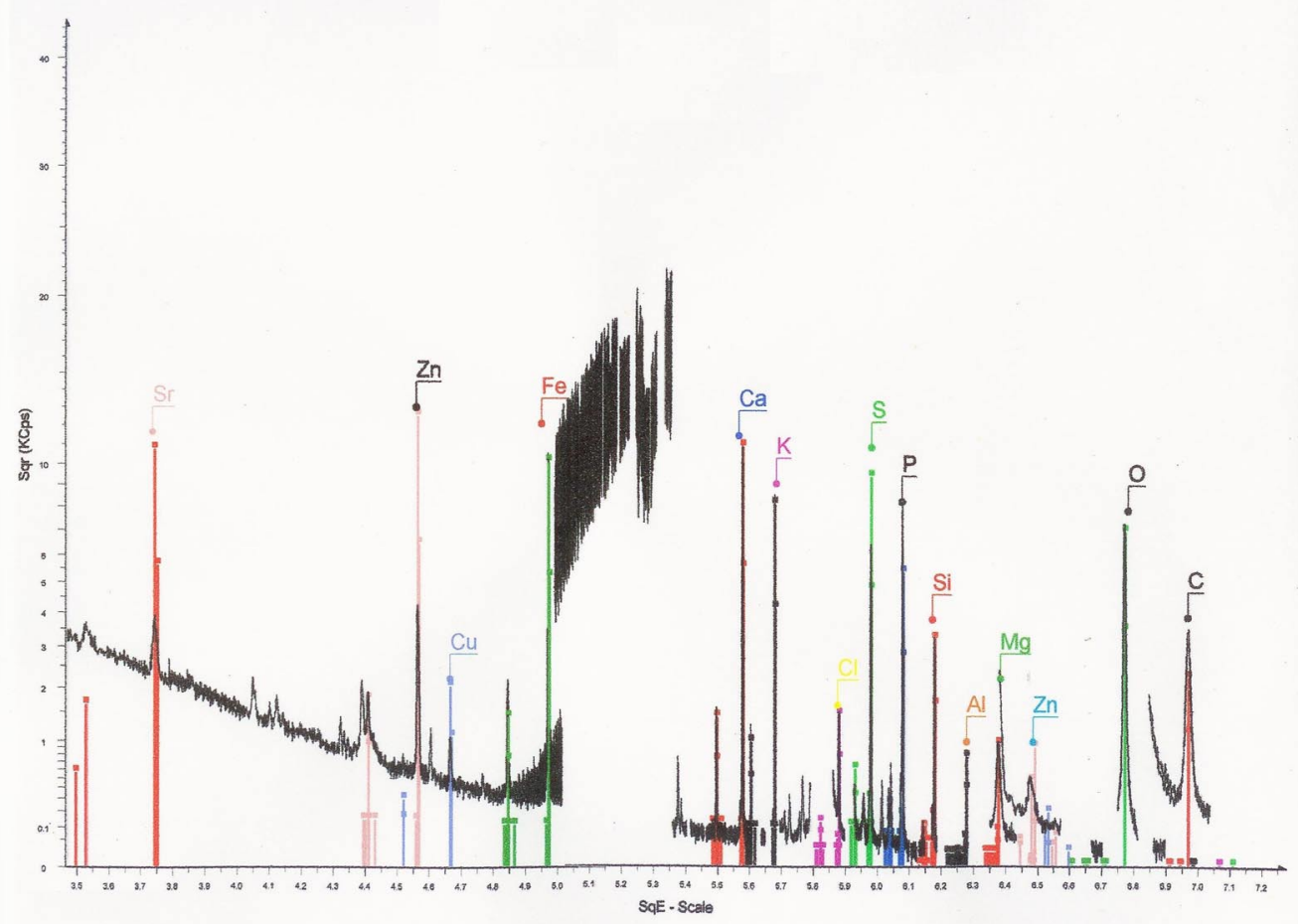

FIGURE S2 Inorganic matter peaks from XRF analysis 


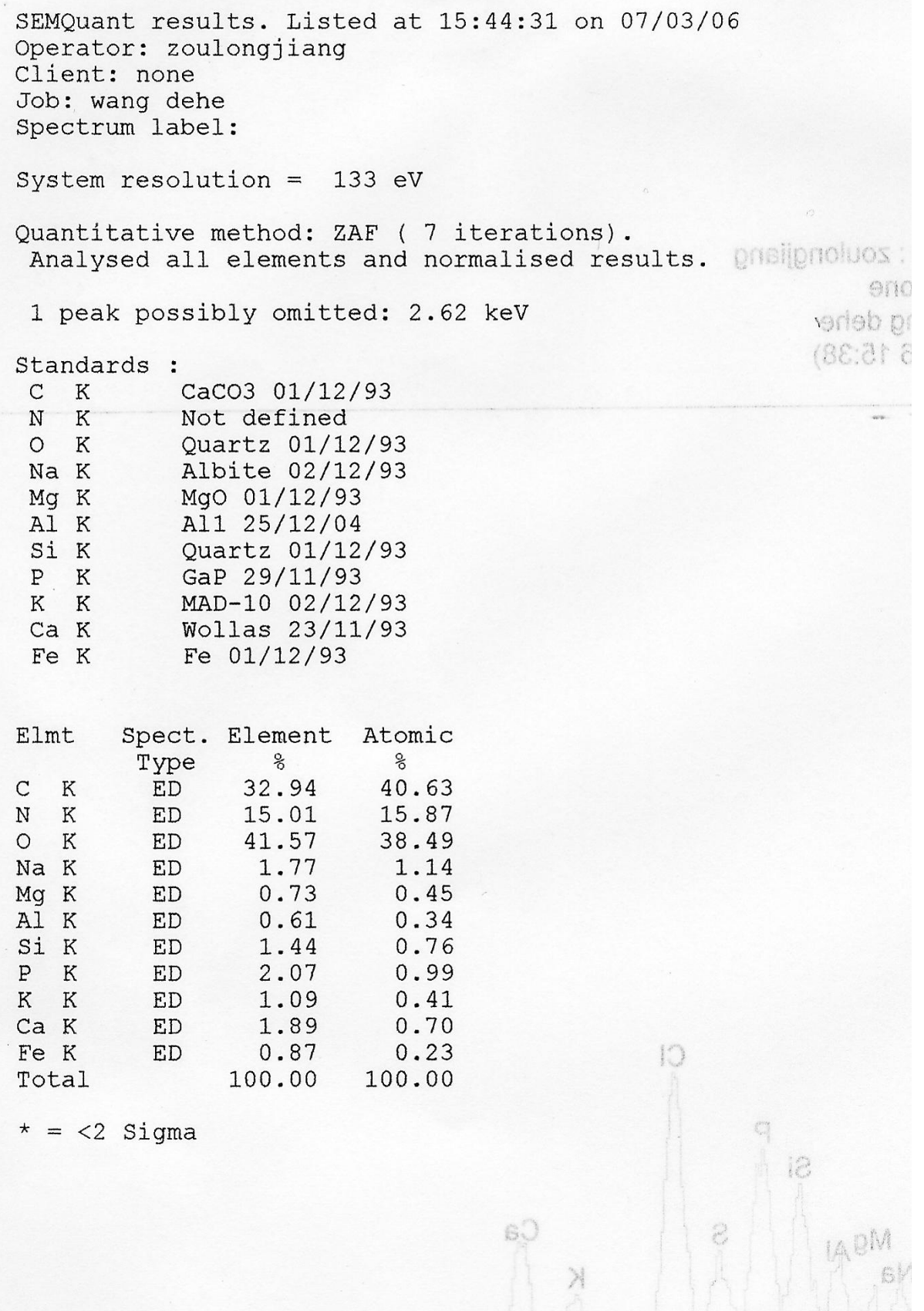

FIGURE S3 Analysed all elements and normalised results by SEM-EDX 